\title{
Convergence theorems for new classes of multivalued hemicontractive-type mappings
}

\section{Felicia O Isiogugu* and Micah O Osilike}

\section{"Correspondence:}

obifeli2001@yahoo.com

Department of Mathematics,

University of Nigeria, Nsukka,

Nigeria

\begin{abstract}
Weak and strong convergence theorems are proved in Hilbert spaces for new classes of multivalued demicontractive-type and hemicontractive-type mappings which are related to the class of multivalued pseudocontractive-type mappings studied by Isiogugu (Fixed Point Theory Appl. 2013:61, 2013). Thus our results extend and improve several corresponding results in the contemporary literature.
\end{abstract}

MSC: $47 \mathrm{H} 10 ; 54 \mathrm{H} 25$

Keywords: Hilbert spaces; demicontractive-type mappings; hemicontractive-type mappings; demiclosedness principle; weak and strong convergence

\section{Introduction}

Let $E$ be a normed space. A subset $K$ of $E$ is called proximinal if for each $x \in E$ there exists $k \in K$ such that

$$
\|x-k\|=\inf \{\|x-y\|: y \in K\}=d(x, K) .
$$

It is well known that every closed convex subset of a uniformly convex Banach space is proximinal. For a nonempty set $E$, we shall denote the family of all nonempty proximinal subsets of $E$ by $P(E)$, the family of all nonempty closed and bounded subsets of $E$ by $C B(E)$, the family of all nonempty closed, convex, and bounded subsets of $E$ by $C V B(E)$, the family of all nonempty closed subsets of $E$ by $C(X)$, the family of all nonempty subsets of $E$ by $2^{E}$, the identity on $E$ by $I$, the weak topology of $E$ by $\sigma\left(E, E^{*}\right)$, and the norm (or strong) topology of $E$ by $(E,\|\cdot\|)$.

Let $H$ denote the Hausdorff metric induced by the metric $d$ on $E$, that is, for every $A, B \in$ $2^{E}$

$$
H(A, B)=\max \left\{\sup _{a \in A} d(a, B), \sup _{b \in B} d(b, A)\right\}
$$

If $A, B \in C B(E)$, then

$$
H(A, B)=\inf \{\epsilon>0: A \subseteq N(\epsilon, B) \text { and } B \subseteq N(\epsilon, A)\}
$$

where $N(\epsilon, C)=\bigcup_{c \in C}\{x \in E: d(x, c)<\epsilon\}$. Let $E$ be a normed space. Let $T: D(T) \subseteq E \rightarrow 2^{E}$ be a multivalued mapping on $E$. A point $x \in D(T)$ is called a fixed point of $T$ if $x \in T x$. The

(2014 Isiogugu and Osilike; licensee Springer. This is an Open Access article distributed under the terms of the Creative Commons Attribution License (http://creativecommons.org/licenses/by/2.0), which permits unrestricted use, distribution, and reproduction in any medium, provided the original work is properly cited. 
set $F(T)=\{x \in D(T): x \in T x\}$ is called the fixed point set of $T$. A point $x \in D(T)$ is called a strict fixed point of $T$ if $T x=\{x\}$. The set $F_{s}(T)=\{x \in D(T): T x=\{x\}\}$ is called the strict fixed point set of $T$. A multivalued mapping $T: D(T) \subseteq E \rightarrow 2^{E}$ is called L-Lipschitzian if there exists $L \geq 0$ such that for all $x, y \in D(T)$

$$
H(T x, T y) \leq L\|x-y\| .
$$

In (1.1) if $L \in[0,1), T$ is said to be a contraction, while $T$ is nonexpansive if $L=1 . T$ is called quasi-nonexpansive if $F(T)=\{x \in D(T): x \in T x\} \neq \emptyset$ and for all $p \in F(T)$,

$$
H(T x, T p) \leq\|x-p\| .
$$

Clearly every nonexpansive mapping with nonempty fixed point set is quasi-nonexpansive.

Several authors have studied various classes of multivalued mappings. In [1], Shahzad and Zegeye studied certain classes of multivalued nonself mappings in Banach spaces and constructed an appropriate net which converges strongly to a fixed point of the classes of the mappings. Recently, Isiogugu [2] introduced new classes of multivalued mappings as follows.

Definition 1.1 ([2]) Let $X$ be a normed space. A multivalued mapping $T: D(T) \subseteq X \rightarrow 2^{X}$ is said to be $k$-strictly pseudocontractive-type in the sense of Browder and Petryshyn [3] if there exists $k \in[0,1)$ such that given any $x, y \in D(T)$ and $u \in T x$, there exists $v \in T y$ satisfying $\|u-v\| \leq H(T x, T y)$ and

$$
H^{2}(T x, T y) \leq\|x-y\|^{2}+k\|x-u-(y-v)\|^{2} .
$$

If $k=1$ in (1.3) $T$ is said to be a pseudocontractive-type mapping. $T$ is called nonexpansive-type if $k=0$. Clearly, every multivalued nonexpansive mapping is nonexpansive-type mapping.

From the definitions, it is clear that every multivalued nonexpansive-type mapping is $k$-strictly pseudocontractive-type and every $k$-strictly pseudocontractive-type mapping is pseudocontractive-type. Examples to show that the class of nonexpansive-type mappings is properly contained in the class of $k$-strictly pseudocontractive-type mappings and that the class of $k$-strictly pseudocontractive-type mappings is properly contained in the class of pseudocontractive-type mappings were given in [2]. The following theorems were also proved in [2].

Theorem 1.1 Let $K$ be a nonempty closed and convex subset of a real Hilbert space $H$. Suppose that $T: K \rightarrow P(K)$ is a $k$-strictly pseudocontractive-type mapping from $K$ into the family of all proximinal subsets of $K$ with $k \in(0,1)$ such that $F(T) \neq \emptyset$ and $T(p)=\{p\}$ for all $p \in F(T)$. Suppose $(I-T)$ is weakly demiclosed at zero. Then the Mann-type sequence defined by

$$
x_{n+1}=\left(1-\alpha_{n}\right) x_{n}+\alpha_{n} y_{n}
$$

converges weakly to $q \in F(T)$, where $y_{n} \in T x_{n}$ with $\left\|x_{n}-y_{n}\right\|=d\left(x_{n}, T x_{n}\right)$ and $\alpha_{n}$ is a real sequence in $(0,1)$ satisfying: (i) $\alpha_{n} \rightarrow \alpha<1-k$; (ii) $\alpha>0$; (iii) $\sum_{n=1}^{\infty} \alpha_{n}\left(1-\alpha_{n}\right)=\infty$. 
Theorem 1.2 Let $K$ be a nonempty closed and convex subset of a real Hilbert space $X$. Suppose that $T: K \rightarrow P(K)$ is an L-Lipschitzian pseudocontractive-type mapping from $K$ into the family of all proximinal subsets of $K$ such that $F(T) \neq \emptyset$ and $T(p)=\{p\}$ for all $p \in F(T)$. Suppose for any pair $x, y \in K$ and $u \in T x$ with $\|x-u\|=d(x, T x)$, there exists $v \in T y$ with $\|y-v\|=d(y, T y)$ satisfying the conditions of Definition 1.1. Suppose T satisfies condition (1) (i.e., if there exists a nondecreasing function $f:[0, \infty) \rightarrow[0, \infty)$ with $f(0)=0$ and $f(r)>0$ for all $r \in(0, \infty)$ such that $d(x, T x) \geq f(d(x, F(T))), \forall x \in K$. Then the Ishikawa sequence defined by

$$
\left\{\begin{array}{l}
y_{n}=\left(1-\beta_{n}\right) x_{n}+\beta_{n} u_{n}, \\
x_{n+1}=\left(1-\alpha_{n}\right) x_{n}+\alpha_{n} w_{n}
\end{array}\right.
$$

converges strongly to $p \in F(T)$, where $u_{n} \in T x_{n}$ with $\left\|x_{n}-u_{n}\right\|=d\left(x_{n}, T x_{n}\right), w_{n} \in T y_{n}$ with $\left\|y_{n}-w_{n}\right\|=d\left(y_{n}, T y_{n}\right)$ satisfying the conditions in Definition 1.1 and $\left\{\alpha_{n}\right\}$ and $\left\{\beta_{n}\right\}$ are real sequences satisfying: (i) $0 \leq \alpha_{n} \leq \beta_{n}<1$; (ii) $\liminf _{n \rightarrow \infty} \alpha_{n}=\alpha>0$; (iii) $\sup _{n \geq 1} \beta_{n} \leq \beta \leq$ $\frac{1}{\sqrt{1+L^{2}}+1}$.

In [4], Chidume et al. also considered a class of multivalued $k$-strictly pseudocontractive mappings defined as follows.

Let $H$ be a real Hilbert space. A multivalued mapping $T: D(T) \subseteq H \rightarrow C B(H)$ is said to be $k$-strictly pseudocontractive if there exists $k \in(0,1)$ such that for all $x, y \in D(T)$ one has

$$
H^{2}(T x, T y) \leq\|x-y\|^{2}+k\|x-u-(y-v)\|^{2}, \quad \forall u \in T x, v \in T y .
$$

If $k=1, T$ is said to be pseudocontractive mapping. They constructed a Mann-type iteration scheme which is an approximate fixed point sequence and obtain some strong convergence theorems for the class of $k$-strictly pseudocontractive mappings.

The following example shows that the class of multivalued pseudocontractive-type mappings considered by Isiogugu [2] is not a subclass of the multivalued pseudocontractive mappings considered by Chidume et al. [4].

Example 1.1 Let $X=\mathbb{R}$ (the reals with usual metric). Define $T:[0, \infty) \rightarrow C B(\mathbb{R})$ by

$$
T x=\left[-\frac{5 x}{2},-2 x\right]
$$

It was shown in [2] that $T$ is $k$-strictly pseudocontractive-type mapping hence pseudocontractive-type. However, for $x=3, y=2$ if we choose $u=-6 \in T x$ and $v=-5 \in T y$ then $H^{2}(T x, T y)=\frac{25}{4}$ and $\|x-y\|^{2}+\|x-u-(y-v)\|^{2}=5$. Consequently,

$$
H^{2}(T x, T y)>\|x-y\|^{2}+\|x-u-(y-v)\|^{2},
$$

which implies that $T$ is not pseudocontractive and hence not $k$-strictly pseudocontractive mapping in the sense of Chidume et al. [4].

It is our purpose in this work to introduce and study new classes of multivalued demicontractive-type and hemicontractive-type mappings which are more general than the class of multivalued quasi-nonexpansive mappings and are also related to the multivalued $k$-strictly pseudocontractive-type and pseudocontractive-type mappings of Isiogugu 
[2], single-valued mappings of Browder and Petryshyn [3], Hicks and Kubicek [5] and Naimpally and Singh [6]. We also prove weak and strong convergence theorems for approximation of fixed points of our classes of mappings.

\section{Preliminaries}

We shall need the following definitions and lemmas.

Definition 2.1 (see, e.g., [7]) Let $E$ be a Banach space. Let $T: D(T) \subseteq E \rightarrow 2^{E}$ be a multivalued mapping. $I-T$ is said to be strongly demiclosed at zero if for any sequence $\left\{x_{n}\right\}_{n=1}^{\infty} \subseteq D(T)$ such that $x_{n}$ converges strongly to $p$ and a sequence $\left\{y_{n}\right\}$ with $y_{n} \in T x_{n}$ for all $n \in \mathbb{N}$ such that $\left\{x_{n}-y_{n}\right\}$ converges strongly to zero, then $p \in T p(i . e ., 0 \in(I-T) p)$.

Observe that if $T$ is a multivalued Lipschitzian mapping, then $I-T$ is strongly demiclosed.

Definition 2.2 (see, e.g., $[7,8]$ ) Let $E$ be a Banach space. Let $T: D(T) \subseteq E \rightarrow 2^{E}$ be a multivalued mapping. $I-T$ is said to be weakly demiclosed at zero if for any sequence $\left\{x_{n}\right\}_{n=1}^{\infty} \subseteq D(T)$ such that $\left\{x_{n}\right\}$ converges weakly to $p$ and a sequence $\left\{y_{n}\right\}$ with $y_{n} \in T x_{n}$ for all $n \in \mathbb{N}$ such that $\left\{x_{n}-y_{n}\right\}$ converges strongly to zero. Then $p \in T p(i . e ., 0 \in(I-T) p)$.

Definition 2.3 (see, e.g., [7, 8]) Let $E$ be a Banach space. Let $T: D(T) \subseteq E \rightarrow 2^{E}$ be a multivalued mapping. The graph of $I-T$ is said to be closed in $\sigma\left(E, E^{*}\right) \times(E,\|\cdot\|)$ (i.e., $I-T$ is weakly demiclosed or demiclosed) if for any sequence $\left\{x_{n}\right\}_{n=1}^{\infty} \subseteq D(T)$ such that $\left\{x_{n}\right\}$ converges weakly to $p$ and a sequence $\left\{y_{n}\right\}$ with $y_{n} \in T x_{n}$ for all $n \in \mathbb{N}$ such that $\left\{x_{n}-y_{n}\right\}$ converges strongly to $y$. Then $y \in(I-T) p$ (i.e., $y=p-v$ for some $v \in T p$ ).

Definition 2.4 A Banach $X$ is said to satisfy Opial's condition if whenever a sequence $\left\{x_{n}\right\}$ converges weakly to $x \in X$ then it is the case that

$$
\liminf \left\|x_{n}-x\right\|<\liminf \left\|x_{n}-y\right\|,
$$

for all $y \in X, y \neq x$.

Definition 2.5 ([9]) A multivalued mapping $T: K \rightarrow P(K)$ is said to satisfy condition (1) (see for example [9]) if there exists a nondecreasing function $f:[0, \infty) \rightarrow[0, \infty)$ with $f(0)=0$ and $f(r)>0$ for all $r \in(0, \infty)$ such that

$$
d(x, T x) \geq f(d(x, F(T))), \quad \forall x \in K
$$

Lemma 2.1 ([10]) Let $\left\{a_{n}\right\},\left\{\beta_{n}\right\}$, and $\left\{\gamma_{n}\right\}$ be sequences of nonnegative real numbers satisfying the following relation:

$$
a_{n+1} \leq\left(1+\beta_{n}\right) a_{n}+\gamma_{n}, \quad n \geq n_{0},
$$

where $n_{0}$ is a nonnegative integer. If $\sum \beta_{n}<\infty, \sum \gamma_{n}<\infty$, then $\lim _{n \rightarrow \infty} a_{n}$ exists.

Lemma 2.2 ([11]) Let $K$ be a normed space. Let $T: K \rightarrow P(K)$ be a multivalued mapping and $P_{T}(x)=\{y \in T x:\|x-y\|=d(x, T x)\}$. Then the following are equivalent: 
(1) $x \in T x$;

(2) $P_{T} x=\{x\}$

(3) $x \in F\left(P_{T}\right)$.

Moreover, $F(T)=F\left(P_{T}\right)$.

Lemma 2.3 ([12]) Let $A, B \in C B(X)$ and $a \in A$. If $\gamma>0$, then there exists $b \in B$ such that

$$
d(a, b) \leq H(A, B)+\gamma .
$$

\section{Main results}

We now introduce the new classes of multivalued demicontractive-type and hemicontractive-type mappings and prove some convergence theorems for these classes of mappings.

Definition 3.1 Let $X$ be a real normed space. A mapping $T: D(T) \subseteq X \rightarrow 2^{X}$ is said to be demicontractive in the terminology of Hicks and Kubicek [5] if $F(T) \neq \emptyset$ and for all $p \in F(T), x \in D(T)$ there exists $k \in[0,1)$ such that

$$
H^{2}(T x, T p) \leq\|x-p\|^{2}+k d^{2}(x, T x)
$$

where $H^{2}(T x, T p)=[H(T x, T p)]^{2}$ and $d^{2}(x, p)=[d(x, p)]^{2}$.

If $k=1$ in (3.1) then $T$ is called a hemicontractive mapping.

The following are some examples of demicontractive mappings.

Example 3.1 Every multivalued quasi-nonexpansive mapping is demicontractive.

Example 3.2 Let $X$ be a normed space. Suppose that $T$ is a multivalued mapping such that $F(T) \neq \emptyset$ and that $P_{T}$ is a $k$-strictly pseudocontractive-type mapping; then $P_{T}$ is demicontractive.

Example 3.3 Let $X$ be a normed space. Let $T: D(T) \subseteq X \rightarrow P(X)$ be a multivalued $k$-strictly pseudocontractive-type with a nonempty fixed point set. Suppose $T p=\{p\}$ for all $p \in F(T)$; then for any $x \in D(T), p \in F(T)$ and $u \in T x$ with $\|u-x\|=d(x, T x)$ we have

$$
H^{2}(T x, T p) \leq\|x-p\|^{2}+k\|x-u\|^{2}=\|x-p\|^{2}+k d^{2}(x, T x) ;
$$

therefore, $T$ is demicontractive-type.

Example 3.4 Let $X=\mathbb{R}$ (the reals with usual metric). Define $T: \mathbb{R} \rightarrow 2^{\mathbb{R}}$ by

$$
T x= \begin{cases}{\left[-\frac{3 x}{2},-2 x\right],} & x \in(-\infty, 0], \\ {\left[-2 x,-\frac{3 x}{2}\right],} & x \in(0, \infty) .\end{cases}
$$

Then $F(T)=\{0\}$. For each $x \in(-\infty, 0) \cup(0, \infty)$,

$$
\begin{aligned}
& H^{2}(T x, T 0)=|-2 x-0|^{2}=4|x-0|^{2}=|x-0|^{2}+3|x|^{2}, \\
& d^{2}(x, T x)=\left|x-\left(-\frac{3 x}{2}\right)\right|^{2}=\left|\frac{5 x}{2}\right|^{2}=\frac{25}{4}|x|^{2} .
\end{aligned}
$$


Therefore,

$$
H^{2}(T x, T 0)=|x-0|^{2}+3|x|^{2}=|x-0|^{2}+\frac{12}{25} d^{2}(x, T x) \leq|x-0|^{2}+k d^{2}(x, T x) .
$$

Consequently, $T$ is demicontractive-type with $k=\frac{12}{25}$. It then follows that $T$ is hemicontractive. Observe that $T$ is not quasi-nonexpansive so that the class of multivalued quasinonexpansive mappings is properly contained in the class of multivalued demicontractivetype mappings.

Next is an example of a multivalued mapping $T$ with $F(T) \neq \emptyset, T p=\{p\}$ for all $p \in T p$ for which $P_{T}$ is a demicontractive-type but not a $k$-strictly pseudocontractive-type mapping.

Example 3.5 Let $X=\mathbb{R}$ (the reals with usual metric). Define $T:[-1,1] \rightarrow 2^{[-1,1]}$ by

$$
T x= \begin{cases}{\left[-1, \frac{2}{3} x \sin \frac{1}{x}\right],} & x \in(0,1], \\ \{0\}, & x=0, \\ {\left[\frac{2}{3} x \sin \frac{1}{x}, 1\right],} & x \in[-1,0) .\end{cases}
$$

Then $F(T)=\{0\}$. For each $x \in[-1,1]$,

$$
P_{T} x= \begin{cases}\left\{\frac{2}{3} x \sin \frac{1}{x}\right\}, & x \neq 0, \\ \{0\}, & x=0,\end{cases}
$$

which is demicontractive-type but not $k$-strictly pseudocontractive-type (see for example [5]).

The following example shows that the class of demicontractive mapping is properly contained in the class of hemicontractive mappings.

Example 3.6 Let $X=\mathbb{R}$ (the reals with the usual metric). Define $T: \mathbb{R} \rightarrow 2^{\mathbb{R}}$ by

$$
T x= \begin{cases}{[-\sqrt{2} x, 0],} & x \in[0, \infty) \\ {[0,-\sqrt{2} x],} & x \in(-\infty, 0)\end{cases}
$$

Then $F(T)=\{0\}$. For each $x \in(-\infty, 0) \cup(0, \infty)$,

$$
\begin{aligned}
& H^{2}(T x, T 0)=|\sqrt{2} x-0|^{2}=2|x-0|^{2}=|x-0|^{2}+|x-0|^{2}, \\
& d^{2}(x, T x)=|x-0|^{2}=|x-0|^{2} .
\end{aligned}
$$

Therefore,

$$
H^{2}(T x, T 0) \leq|x-0|^{2}+|x-0|^{2}=|x-0|^{2}+d^{2}(x, T x)>|x-0|^{2}+k d^{2}(x, T x),
$$

$\forall x \in \mathbb{B}$ and $\forall k \in[0,1)$. Therefore, $T$ is hemicontractive but not demicontractive.

Other examples of hemicontractive mappings include the following. 
Example 3.7 Let $X$ be a normed space. Suppose $T$ is a multivalued mapping such that $F(T) \neq \emptyset$ and $P_{T}$ is pseudocontractive-type mapping; then $P_{T}$ is hemicontractive.

Example 3.8 Let $X$ be a normed space. Let $T: D(T) \subseteq X \rightarrow P(X)$ be a multivalued pseudocontractive-type with a nonempty fixed point set. Suppose $T p=\{p\}$ for all $p \in F(T)$; then for any $x \in D(T), p \in F(T)$ and $u \in T x$ with $\|u-x\|=d(x, T x)$ we have

$$
H^{2}(T x, T p) \leq\|x-p\|^{2}+\|x-u\|^{2}=\|x-p\|^{2}+d^{2}(x, T x) .
$$

The following lemma shows that Lemma 2.3 is also valid for all $A, B \in P(E)$ and $\gamma=0$.

Lemma 3.1 Let $E$ be a metric space. If $A, B \in P(E)$ and $a \in A$, then it is a simple consequence of the Hausdorff metric $H$ that there exists $b \in B$ such that

$$
d(a, b) \leq H(A, B) .
$$

Proof Let $E$ be a metric space and $P(E)$ be the family of all nonempty proximinal subsets of $E$. Let $A, B \in P(E)$ and $a \in A$. Since $B$ is proximinal, there exists $b_{a} \in B$ such that

$$
d(a, B)=d\left(a, b_{a}\right) .
$$

Observe that

$$
\begin{aligned}
H(A, B) & =\max \left\{\sup _{u \in A} d(u, B), \sup _{v \in B} d(v, A)\right\} \\
& \geq \sup _{u \in A} d(u, B) \geq d(a, B)=d\left(a, b_{a}\right) .
\end{aligned}
$$

Hence the result follows.

Remark 3.1 Lemma 3.1 holds if $E$ is a reflexive real Banach space and $P(E)$ is replaced with $C B(K)$ with $B$ weakly closed (see for example [4]).

We now prove the following theorems.

Theorem 3.1 Let $K$ be a nonempty closed and convex subset of a real Hilbert space $H$. Suppose that $T: K \rightarrow P(K)$ is a demicontractive mapping from $K$ into the family of all proximinal subsets of $K$ with $k \in(0,1)$ and $T(p)=\{p\}$ for all $p \in F(T)$. Suppose $(I-T)$ is weakly demiclosed at zero. Then the Mann type sequence defined by

$$
x_{n+1}=\left(1-\alpha_{n}\right) x_{n}+\alpha_{n} y_{n}
$$

converges weakly to $q \in F(T)$, where $y_{n} \in T x_{n}$ and $\alpha_{n}$ is a real sequence in $(0,1)$ satisfying: (i) $\alpha_{n} \rightarrow \alpha<1-k$; (ii) $\alpha>0$.

Proof Using the well-known identity:

$$
\|t x+(1-t) y\|^{2}=t\|x\|^{2}+(1-t)\|y\|^{2}-t(1-t)\|x-y\|^{2},
$$


which holds for all $x, y \in H$ and for all $t \in[0,1]$, we obtain

$$
\begin{aligned}
\left\|x_{n+1}-p\right\|^{2}= & \left\|\left(1-\alpha_{n}\right) x_{n}+\alpha_{n} y_{n}-p\right\|^{2} \\
= & \left\|\left(1-\alpha_{n}\right)\left(x_{n}-p\right)+\alpha_{n}\left(y_{n}-p\right)\right\|^{2} \\
= & \left(1-\alpha_{n}\right)\left\|x_{n}-p\right\|^{2}+\alpha_{n}\left\|y_{n}-p\right\|^{2}-\alpha_{n}\left(1-\alpha_{n}\right)\left\|x_{n}-y_{n}\right\|^{2} \\
\leq & \left(1-\alpha_{n}\right)\left\|x_{n}-p\right\|^{2}+\alpha_{n} H^{2}\left(T x_{n}, T p\right)-\alpha_{n}\left(1-\alpha_{n}\right)\left\|x_{n}-y_{n}\right\|^{2} \\
\leq & \left(1-\alpha_{n}\right)\left\|x_{n}-p\right\|^{2}+\alpha_{n}\left[\left\|x_{n}-p\right\|^{2}+k d^{2}\left(x_{n}, T x_{n}\right)\right] \\
& -\alpha_{n}\left(1-\alpha_{n}\right)\left\|x_{n}-y_{n}\right\|^{2} \\
\leq & \left\|x_{n}-p\right\|^{2}+\alpha_{n} k\left\|x_{n}-y_{n}\right\|^{2} \\
& -\alpha_{n}\left(1-\alpha_{n}\right)\left\|x_{n}-y_{n}\right\|^{2} \\
= & \left\|x_{n}-p\right\|^{2}-\alpha_{n}\left(1-\left(\alpha_{n}+k\right)\right)\left\|x_{n}-y_{n}\right\|^{2} .
\end{aligned}
$$

It then follows that $\lim _{n \rightarrow \infty}\left\|x_{n}-p\right\|$ exists; hence $\left\{x_{n}\right\}$ is bounded. Also,

$$
\sum_{n=1}^{\infty} \alpha_{n}\left(1-\left(\alpha_{n}+k\right)\right)\left\|x_{n}-y_{n}\right\|^{2} \leq\left\|x_{0}-p\right\|^{2}<\infty
$$

Since $\alpha>0$ from (ii), we have $\lim _{n \rightarrow \infty}\left\|x_{n}-y_{n}\right\|=0$. Thus $\lim _{n \rightarrow \infty} d\left(x_{n}, T x_{n}\right)=0$. Also since $K$ is closed and $\left\{x_{n}\right\} \subseteq K$ with $\left\{x_{n}\right\}$ bounded, there exist a subsequence $\left\{x_{n_{t}}\right\} \subseteq\left\{x_{n}\right\}$ such that $\left\{x_{n_{t}}\right\}$ converges weakly to some $q \in K$. Also $\lim _{n \rightarrow \infty}\left\|x_{n}-y_{n}\right\|=0$ implies that $\lim _{n \rightarrow \infty}\left\|x_{n_{t}}-y_{n_{t}}\right\|=0$. Since $(I-T)$ is weakly demiclosed at zero we have $q \in T q$. Since $H$ satisfies Opial's condition [13] we find that $\left\{x_{n}\right\}$ converges weakly to $q \in F(T)$.

Corollary 3.1 Let $K$ be a nonempty closed and convex subset of a real Hilbert space $H$. Suppose that $T: K \rightarrow P(K)$ is $k$-strictly pseudocontractive-type mapping from $K$ into the family of all proximinal subsets of $K$ with $k \in(0,1)$ such that $F(T) \neq \emptyset$ and $T(p)=\{p\}$ for all $p \in F(T)$. Suppose $(I-T)$ is weakly demiclosed at zero. Then the Mann sequence $\left\{x_{n}\right\}$ defined in Theorem 3.1 converges weakly to a point of $F(T)$.

Proof The proof follows easily from Example 3.3 and Theorem 3.1.

Corollary 3.2 Let $H$ be a real Hilbert space and $K$ a nonempty closed and convex subset of $H$. Let $T: K \rightarrow P(K)$ be a multivalued mapping from $K$ into the family of all proximinal subsets of $K$. Suppose $P_{T}$ is a demicontractive mapping with $k \in(0,1)$ and $\left(I-P_{T}\right)$ is weakly demiclosed at zero. Then the Mann sequence $\left\{x_{n}\right\}$ defined in Theorem 3.1 converges weakly to a point of $F(T)$.

Proof The proof follows easily from Lemma 2.2 and Theorem 3.1.

Remark 3.2 Since the choice of $y_{n} \in T x_{n}$ in the Mann-type iteration scheme is independent of $d\left(x_{n}, T x_{n}\right)$, we can also replace $P(K)$ with $C B(K)$ in Theorem 3.1 and its corollaries. Furthermore, since $\lim _{n \rightarrow \infty} d\left(x_{n}, T x_{n}\right)=0$, one can impose standard conditions on $T$ or $K$ which guarantee strong convergence. 
Theorem 3.2 Let $K$ be a nonempty closed and convex subset of a real Hilbert space $X$. Suppose that $T: K \rightarrow P(K)$ is an L-Lipschitzian hemicontractive mapping from $K$ into the family of all proximinal subsets of $K$ and $T p=\{p\}$ for all $p \in F(T)$. Suppose $T$ satisfies condition (1). Then the Ishikawa sequence defined by

$$
\left\{\begin{array}{l}
y_{n}=\left(1-\beta_{n}\right) x_{n}+\beta_{n} u_{n}, \\
x_{n+1}=\left(1-\alpha_{n}\right) x_{n}+\alpha_{n} w_{n}
\end{array}\right.
$$

converges strongly to $p \in F(T)$, where $u_{n} \in T x_{n}, w_{n} \in T y_{n}$ satisfying the conditions of Lemma 3.1 and $\left\{\alpha_{n}\right\}$ and $\left\{\beta_{n}\right\}$ are real sequences satisfying: (i) $0 \leq \alpha_{n} \leq \beta_{n}<1$; (ii) $\liminf _{n \rightarrow \infty} \alpha_{n}=\alpha>0$; (iii) $\sup _{n \geq 1} \beta_{n} \leq \beta \leq \frac{1}{\sqrt{1+L^{2}}+1}$.

Proof

$$
\begin{aligned}
\left\|x_{n+1}-p\right\|^{2}= & \left\|\left(1-\alpha_{n}\right) x_{n}+\alpha_{n} w_{n}-p\right\|^{2} \\
= & \left\|\left(1-\alpha_{n}\right)\left(x_{n}-p\right)+\alpha_{n}\left(w_{n}-p\right)\right\|^{2} \\
= & \left(1-\alpha_{n}\right)\left\|x_{n}-p\right\|^{2}+\alpha_{n}\left\|w_{n}-p\right\|^{2} \\
& -\alpha_{n}\left(1-\alpha_{n}\right)\left\|x_{n}-w_{n}\right\|^{2} \\
\leq & \left(1-\alpha_{n}\right)\left\|x_{n}-p\right\|^{2}+\alpha_{n} H^{2}\left(T y_{n}, T p\right) \\
& -\alpha_{n}\left(1-\alpha_{n}\right)\left\|x_{n}-w_{n}\right\|^{2} \\
\leq & \left(1-\alpha_{n}\right)\left\|x_{n}-p\right\|^{2}+\alpha_{n}\left[\left\|y_{n}-p\right\|^{2}\right. \\
& \left.+d^{2}\left(y_{n}, T y_{n}\right)\right]-\alpha_{n}\left(1-\alpha_{n}\right)\left\|x_{n}-w_{n}\right\|^{2} \\
= & \left(1-\alpha_{n}\right)\left\|x_{n}-p\right\|^{2}+\alpha_{n}\left\|y_{n}-p\right\|^{2}+\alpha_{n} d^{2}\left(y_{n}, T y_{n}\right) \\
& -\alpha_{n}\left(1-\alpha_{n}\right)\left\|x_{n}-w_{n}\right\|^{2}, \\
\leq & \left\|y_{n}-w_{n}\right\|^{2} \\
= & \left\|\left(1-\beta_{n}\right) x_{n}+\beta_{n} u_{n}-w_{n}\right\|^{2} \\
= & \left\|\left(1-\beta_{n}\right)\left(x_{n}-w_{n}\right)+\beta_{n}\left(u_{n}-w_{n}\right)\right\|^{2} \\
d^{2}\left(y_{n}, T y_{n}\right) & \left(1-\beta_{n}\right)\left\|x_{n}-w_{n}\right\|^{2}+\beta_{n}\left\|u_{n}-w_{n}\right\|^{2} \\
& -\beta_{n}\left(1-\beta_{n}\right)\left\|x_{n}-u_{n}\right\|^{2} . \\
&
\end{aligned}
$$

Equations (3.11) and (3.12) imply that

$$
\begin{aligned}
\left\|x_{n+1}-p\right\|^{2} \leq & \left(1-\alpha_{n}\right)\left\|x_{n}-p\right\|^{2}+\alpha_{n}\left\|y_{n}-p\right\|^{2} \\
& +\alpha_{n}\left[\left(1-\beta_{n}\right)\left\|x_{n}-w_{n}\right\|^{2}+\beta_{n}\left\|u_{n}-w_{n}\right\|^{2}\right. \\
& \left.-\beta_{n}\left(1-\beta_{n}\right)\left\|x_{n}-u_{n}\right\|^{2}\right] \\
& -\alpha_{n}\left(1-\alpha_{n}\right)\left\|x_{n}-w_{n}\right\|^{2}, \\
\left\|y_{n}-p\right\|^{2}=\left\|\left(1-\beta_{n}\right) x_{n}+\beta_{n} u_{n}-p\right\|^{2} & \\
= & \left\|\left(1-\beta_{n}\right)\left(x_{n}-p\right)+\beta_{n}\left(u_{n}-p\right)\right\|^{2}
\end{aligned}
$$




$$
\begin{aligned}
= & \left(1-\beta_{n}\right)\left\|x_{n}-p\right\|^{2}+\beta_{n}\left\|u_{n}-p\right\|^{2}-\beta_{n}\left(1-\beta_{n}\right)\left\|x_{n}-u_{n}\right\|^{2} \\
\leq & \left(1-\beta_{n}\right)\left\|x_{n}-p\right\|^{2}+\beta_{n} H^{2}\left(T x_{n}, T p\right)-\beta_{n}\left(1-\beta_{n}\right)\left\|x_{n}-u_{n}\right\|^{2} \\
\leq & \left(1-\beta_{n}\right)\left\|x_{n}-p\right\|^{2}+\beta_{n}\left[\left\|x_{n}-p\right\|^{2}+d^{2}\left(x_{n}, T x_{n}\right)\right] \\
& -\beta_{n}\left(1-\beta_{n}\right)\left\|x_{n}-u_{n}\right\|^{2} \\
\leq & \left(1-\beta_{n}\right)\left\|x_{n}-p\right\|^{2}+\beta_{n}\left\|x_{n}-p\right\|^{2}+\beta_{n}\left\|x_{n}-u_{n}\right\|^{2} \\
& -\beta_{n}\left(1-\beta_{n}\right)\left\|x_{n}-u_{n}\right\|^{2} \\
= & \left\|x_{n}-p\right\|^{2}+\beta_{n}^{2}\left\|x_{n}-u_{n}\right\|^{2} .
\end{aligned}
$$

Equations (3.13) and (3.14) imply that

$$
\begin{aligned}
\left\|x_{n+1}-p\right\|^{2} \leq & \left(1-\alpha_{n}\right)\left\|x_{n}-p\right\|^{2} \\
& +\alpha_{n}\left[\left\|x_{n}-p\right\|^{2}+\beta_{n}^{2}\left\|x_{n}-u_{n}\right\|^{2}\right] \\
& +\alpha_{n}\left[\left(1-\beta_{n}\right)\left\|x_{n}-w_{n}\right\|^{2}+\beta_{n}\left\|u_{n}-w_{n}\right\|^{2}\right. \\
& \left.-\beta_{n}\left(1-\beta_{n}\right)\left\|x_{n}-u_{n}\right\|^{2}\right] \\
& -\alpha_{n}\left(1-\alpha_{n}\right)\left\|x_{n}-w_{n}\right\|^{2} \\
= & \left(1-\alpha_{n}\right)\left\|x_{n}-p\right\|^{2}+\alpha_{n}\left\|x_{n}-p\right\|^{2}+\alpha_{n} \beta_{n}^{2}\left\|x_{n}-u_{n}\right\|^{2} \\
& +\alpha_{n}\left(1-\beta_{n}\right)\left\|x_{n}-w_{n}\right\|^{2}+\alpha_{n} \beta_{n}\left\|u_{n}-w_{n}\right\|^{2} \\
& -\alpha_{n} \beta_{n}\left(1-\beta_{n}\right)\left\|x_{n}-u_{n}\right\|^{2}-\alpha_{n}\left(1-\alpha_{n}\right)\left\|x_{n}-w_{n}\right\|^{2} \\
\leq & \left\|x_{n}-p\right\|^{2}+\alpha_{n} \beta_{n}^{2}\left\|x_{n}-u_{n}\right\|^{2}+\alpha_{n} \beta_{n} H^{2}\left(T x_{n}, T y_{n}\right) \\
& -\alpha_{n}\left(\beta_{n}-\alpha_{n}\right)\left\|x_{n}-w_{n}\right\|^{2} \\
& -\alpha_{n} \beta_{n}\left(1-\beta_{n}\right)\left\|x_{n}-u_{n}\right\|^{2} \\
\leq & \left\|x_{n}-p\right\|^{2}+\alpha_{n} \beta_{n}^{2}\left\|x_{n}-u_{n}\right\|^{2}+\alpha_{n} \beta_{n}^{3} L^{2}\left\|x_{n}-u_{n}\right\|^{2} \\
& -\alpha_{n} \beta_{n}\left(1-\beta_{n}\right)\left\|x_{n}-u_{n}\right\|^{2} \\
& -\alpha_{n}\left(\beta_{n}-\alpha_{n}\right)\left\|x_{n}-w_{n}\right\|^{2} \\
= & \left\|x_{n}-p\right\|^{2}-\alpha_{n} \beta_{n}\left[1-2 \beta_{n}-L^{2} \beta_{n}^{2}\right]\left\|x_{n}-u_{n}\right\|^{2} \\
& -\alpha_{n}\left(\beta_{n}-\alpha_{n}\right)\left\|x_{n}-w_{n}\right\|^{2} \\
= & \left\|x_{n}-p\right\|^{2}-\alpha_{n} \beta_{n}\left[1-2 \beta_{n}-L^{2} \beta_{n}^{2}\right]\left\|x_{n}-u_{n}\right\|^{2} . \\
&
\end{aligned}
$$

It then follows from Lemma 2.1 that $\lim _{n \rightarrow \infty}\left\|x_{n}-p\right\|$ exists. Hence $\left\{x_{n}\right\}$ is bounded so $\left\{u_{n}\right\}$ and $\left\{w_{n}\right\}$ also are. We then have from (3.15), (ii), and (iii)

$$
\begin{aligned}
\sum_{n=0}^{\infty} \alpha^{2}\left[1-2 \beta-L^{2} \beta^{2}\right]\left\|x_{n}-u_{n}\right\|^{2} & \leq \sum_{n=0}^{\infty} \alpha_{n} \beta_{n}\left[1-2 \beta_{n}-L^{2} \beta_{n}^{2}\right]\left\|x_{n}-u_{n}\right\|^{2} \\
& \leq \sum_{n=0}^{\infty}\left[\left\|x_{n}-p\right\|^{2}-\left\|x_{n+1}-p\right\|^{2}\right] \\
& \leq\left\|x_{0}-p\right\|^{2}+D<\infty .
\end{aligned}
$$


It then follows that $\lim _{n \rightarrow \infty}\left\|x_{n}-u_{n}\right\|=0$. Since $u_{n} \in T x_{n}$ we have $d\left(x_{n}, T x_{n}\right) \leq\left\|x_{n}-u_{n}\right\| \rightarrow$ 0 as $n \rightarrow \infty$. Since $T$ satisfies condition (1), $\lim _{n \rightarrow \infty} d\left(x_{n}, F(T)\right)=0$. Thus there exists a subsequence $\left\{x_{n_{k}}\right\}$ of $\left\{x_{n}\right\}$ such that $\left\|x_{n_{k}}-p_{k}\right\| \leq \frac{1}{2^{k}}$ for some $\left\{p_{k}\right\} \subseteq F(T)$. From (3.10)

$$
\left\|x_{n_{k+1}}-p_{k}\right\| \leq\left\|x_{n_{k}}-p_{k}\right\|
$$

We now show that $\left\{p_{k}\right\}$ is a Cauchy sequence in $F(T)$. We have

$$
\begin{aligned}
\left\|p_{k+1}-p_{k}\right\| & \leq\left\|p_{k+1}-x_{n_{k+1}}\right\|+\left\|x_{n_{k+1}}-p_{k}\right\| \\
& \leq \frac{1}{2^{k+1}}+\frac{1}{2^{k}} \\
& =\frac{1}{2^{k-1}} .
\end{aligned}
$$

Therefore $\left\{p_{k}\right\}$ is a Cauchy sequence and converges to some $q \in K$ because $K$ is closed. Now,

$$
\left\|x_{n_{k}}-q\right\| \leq\left\|x_{n}-p_{k}\right\|+\left\|p_{k}-q\right\| \text {. }
$$

Hence $x_{n_{k}} \rightarrow q$ as $k \rightarrow \infty$. We have

$$
\begin{aligned}
d(q, T q) & \leq\left\|q-p_{k}\right\|+\left\|p_{k}-x_{n_{k}}\right\|+d\left(x_{n_{k}}, T x_{n_{k}}\right)+H\left(T x_{n_{k}}, T q\right) \\
& \leq\left\|q-p_{k}\right\|+\left\|p_{k}-x_{n_{k}}\right\|+d\left(x_{n_{k}}, T x_{n_{k}}\right)+L\left\|x_{n_{k}}-q\right\| .
\end{aligned}
$$

Hence, $q \in T q$ and $\left\{x_{n_{k}}\right\}$ converges strongly to $q$. Since $\lim \left\|x_{n}-q\right\|$ exists we see that $x_{n}$ converges strongly to $q \in F(T)$.

Corollary 3.3 Let $K$ be a nonempty closed and convex subset of a real Hilbert space $X$. Suppose that $T: K \rightarrow P(K)$ is an L-Lipschitzian pseudocontractive-type mapping from $K$ into the family of all proximinal subsets of $K$ such that $F(T) \neq \emptyset$ and $T(p)=\{p\}$ for all $p \in F(T)$. Suppose $T$ satisfies condition (1). Then the Ishikawa sequence $\left\{x_{n}\right\}$ defined in (3.10) converges strongly to $p \in F(T)$.

Proof The proof follows easily from Example 3.8, Lemma 3.1, and Theorem 3.2.

Corollary 3.4 Let $H$ be a real Hilbert space and $K$ a nonempty closed and convex subset of $H$. Let $T: K \rightarrow P(K)$ be a multivalued mapping from $K$ into the family of all proximinal subsets of $K$ such that $F(T) \neq \emptyset$. Suppose $P_{T}$ is an L-Lipschitzian hemicontractive mapping. If $T$ satisfies condition (1). Then the Ishikawa sequence $\left\{x_{n}\right\}$ defined in (3.10) converges strongly to $p \in F(T)$.

Proof The proof follows easily from Lemma 2.2 and Theorem 3.2.

Remark 3.3 In Theorem 3.2 and its corollaries we can replace $P(K)$ with $C B(K)$ with additional condition that $T$ is weakly closed for all $x \in D(T)=K$ in order to ensure that $u_{n}$ and $w_{n}$ satisfy Lemma 3.1 as indicated in Remark 3.1. Furthermore, since $\lim _{n \rightarrow \infty} d\left(x_{n}, T x_{n}\right)=$ 0 , the additional requirement that $(I-T)$ is weakly demiclosed at zero in Theorem 3.2 yields weak convergence without condition (1). 


\section{Competing interests}

The authors declare that they have no competing interests.

\section{Authors' contributions}

All authors contributed equally to the writing of this paper. All authors read and approved the final manuscript.

\section{Acknowledgements}

The second author is grateful to the Abdus Salam International Centre for Theoretical Physics (ICTP), Trieste, Italy for their facilities and for hospitality. He contributed to the work during his visits to the Centre as a regular associate. The work was completed while the first author was visiting the University of Kwazulu Natal, South Africa under the OWSD (formally TWOWS) Postgraduate Training Fellowship. She is grateful to OWSD (formally TWOWS) for the Fellowship and to University of Kwazulu Natal for making facilities available and for hospitality.

Received: 27 September 2013 Accepted: 13 February 2014 Published: 09 Apr 2014

\section{References}

1. Shahzad, N, Zegeye, $\mathrm{H}$ : Strong convergence results for nonself multimaps in Banach spaces. Proc. Am. Math. Soc. 136(2), 539-548 (2008)

2. Isiogugu, FO: Demiclosedness principle and approximation theorems for certain classes of multivalued mappings in Hilbert spaces. Fixed Point Theory Appl. 2013, 61 (2013)

3. Browder, FE, Petryshyn, WV: Construction of fixed points of nonlinear mappings in Hilbert spaces. J. Math. Anal. Appl. 20, 197-228 (1967)

4. Chidume, CE, Chidume, CO, Djitté, N, Minjibir, MS: Convergence theorems for fixed points multivalued strictly pseudocontractive mappings in Hilbert spaces. Abstr. Appl. Anal. 2013, Article ID 629468 (2013)

5. Hicks, TL, Kubicek, JD: On the Mann iteration process in a Hilbert space. J. Math. Anal. Appl. 59, 498-504 (1977)

6. Naimpally, SA, Singh, KL: Extensions of some fixed point theorems of Rhoades. J. Math. Anal. Appl. 96, 437-446 (1983)

7. Garcia-Falset, J, Lorens-Fuster, E, Suzuki, T: Fixed point theory for a class of generalised nonexpansive mappings. J. Math. Anal. Appl. 375, 185-195 (2011)

8. Dozo, EL: Multivalued nonexpansive mappings and Opial's condition. Proc. Am. Math. Soc. 38(2), $286-292$ (1973)

9. Song, Y, Wang, H: Erratum to 'Mann and Ishikawa iterative processes for multivalued mappings in Banach spaces' [Comput. Math. Appl. 54 (2007) 872-877]. Comput. Math. Appl. 55, 2999-3002 (2008)

10. Osilike, MO, Aniagbaoso, SC, Akuchu, BG: Fixed points of asymptotically demicontractive mappings in arbitrary Banach spaces. Panam. Math. J. 12(2), 77-88 (2002)

11. Song, Y, Cho, YJ: Some notes on Ishikawa iteration for multivalued mappings. Bull. Korean Math. Soc. 48(3), 575-584 (2011). doi:10.4134/BKMS.2011.48.3.575

12. Nadler, SB Jr.: Multivalued contraction mappings. Pac. J. Math. 30, 475-488 (1969)

13. Opial, Z: Weak convergence of the sequence of successive approximations for nonexpansive mappings. Bull. Am. Math. Soc. 73, 591-597 (1967)

10.1186/1687-1812-2014-93

Cite this article as: Isiogugu and Osilike: Convergence theorems for new classes of multivalued

hemicontractive-type mappings. Fixed Point Theory and Applications 2014, 2014:93

\section{Submit your manuscript to a SpringerOpen ${ }^{\odot}$ journal and benefit from:}

- Convenient online submission

- Rigorous peer review

- Immediate publication on acceptance

- Open access: articles freely available online

- High visibility within the field

- Retaining the copyright to your article 